\title{
Dutch women with a low birth weight have an increased risk of myocardial infarction later in life: a case control study Bea C Tanis ${ }^{1}$, Kitty Kapiteijn ${ }^{2}$, Ronella M Hage ${ }^{2}$, Frits R Rosendaal ${ }^{1,3}$ and Frans M Helmerhorst*2
}

Address: ${ }^{1}$ Department of Hematology, Leiden University Medical Center, Leiden, The Netherlands, ${ }^{2}$ Department of Gynecology and Reproductive Medicine, Leiden University Medical Center, The Netherlands and ${ }^{3}$ Department of Clinical Epidemiology, Leiden University Medical Center, The Netherlands

Email: Bea C Tanis - b.tanis@planet.nl; Kitty Kapiteijn - k_kapiteijn@hotmail.com; Ronella M Hage - ronellahage@hotmail.com; Frits R Rosendaal - F.R.Rosendaal@lumc.nl; Frans M Helmerhorst* - F.M.Helmerhorst@LUMC.nl

* Corresponding author

Published: 10 January 2005

Reproductive Health 2005, 2:1 doi:10.1 186/1742-4755-2-1
Received: 17 November 2004

Accepted: 10 January 2005

This article is available from: http://www.reproductive-health-journal.com/content/2/l/I

(c) 2005 Tanis et al; licensee BioMed Central Ltd.

This is an Open Access article distributed under the terms of the Creative Commons Attribution License (http://creativecommons.org/licenses/by/2.0), which permits unrestricted use, distribution, and reproduction in any medium, provided the original work is properly cited.

\begin{abstract}
Background: To investigate whether low birth weight increases the risk of myocardial infarction later in life in women.

Methods: Nationwide population-based case-control study. Patients and controls: 152 patients with a first myocardial infarction before the age of 50 years in the Netherlands. 568 control women who had not had a myocardial infarction stratified for age, calendar year of the index event, and area of residence.
\end{abstract}

Results: Birth weight in the patient group was significantly lower than in control women (3214 vs. 3370 gram, mean difference -156.3 gram $(95 \% \mathrm{Cl}-9.5$ to -303.1$)$. The odds ratio for myocardial infarction, associated with a birth weight lower than 3000 gram (20th percentile in controls)

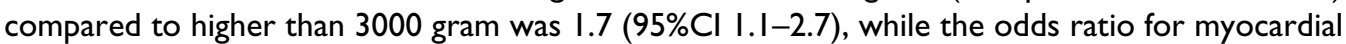
infarction for children with a low birth weight $(<2000 \mathrm{~g}$ ) compared to a birth weight $\geq 2000 \mathrm{~g}$ was $2.4(95 \% \mathrm{Cl} \mathrm{I.0}-5.8)$. Both figures did not change after adjustment for putative confounders (age, education level, body mass index, waist-hip ratio, hypertension, diabetes, hypercholesterolemia, smoking, and family history of cardiovascular disease).

Conclusions: Low birth weight is associated with an increased risk of myocardial infarction before age of 50 in Dutch women.

\section{Background}

Intrauterine malnutrition, as reflected by birth weight and abnormal thinness at birth, has been associated with an increased incidence of risk factors for arterial disease, i.e. hypertension, impaired glucose tolerance, diabetes and to a lesser extent hyperlipidemia and body fat distribution in adulthood [1-10]. This observation has become known as the 'fetal origins of adult disease' or 'Barker hypothesis', which suggests that several of the major diseases of later life, including coronary heart disease, stroke and cardiovascular death, originate in impaired intrauterine growth and development $[11,12]$. In cohort studies, Barker [1315] in England and Finland, Rich-Edwards et al. [16] as part of the Nurses' Health Study in the USA and Leon et al. 
[17] from Uppsala in Sweden showed an inverse relationship between birth weight and the clinical endpoint ischemic heart disease. Leon et al. [17] found a significant relationship only among male singletons and adjusted their results for gestational age and socioeconomic confounding. The association was not found in a cohort study from Gothenburg [18].

Our aim was to investigate the association in a case control study among Dutch women.

\section{Methods}

The RATIO (Risk of Arterial Thrombosis In relation to Oral contraceptives) study is a population-based casecontrol study on myocardial infarction in relation to oral contraceptive use among women aged 18 to 49 years in the Netherlands [19]. An additional standardized questionnaire was sent to all 218 patients and 769 controls from whom also blood samples had been taken for determination of metabolic risk factors (diabetes and hypercholesterolemia). Questions elicited information on birth weight, waist and hip circumference and data on the menstrual cycle. For 13 women no current address could be found (12 patients, 1 control). Four women had died since the index date ( 2 patients, 2 controls), which was the date of the first myocardial infarction for the patients and the midyear for the controls. One hundred and fifty two patients (71\%) and 568 controls (75\%) responded to the questionnaire and women were asked to measure their waist and hip circumference. Body mass index (BMI) was calculated as body weight ( $\mathrm{kg}$ ) divided by height squared $\left(\mathrm{m}^{2}\right)$. Waist-hip-ratio was calculated as waist circumference divided by hip circumference.

Multiple linear and unconditional logistic regression were used to analyze the data. Odds ratios for the relationship between birth weight and myocardial infarction were calculated and 95\% confidence intervals (95\% CI) were derived from the models. Birth weights were categorized according to quintiles in control women in order to investigate an association between birth weight and the risk of myocardial infarction later in life. These were $<3000 \mathrm{~g}$, 3000 to $3199 \mathrm{~g}, 3200$ to $3499 \mathrm{~g}, 3500$ to $3883 \mathrm{~g}$, and $>3884 \mathrm{~g}$, respectively. To determine whether women with a lower birth weight had a higher risk for a myocardial infarction, patients were divided in a group with a birth weight equally or higher than $2000 \mathrm{~g}$ and a group with a birth weight lower $2000 \mathrm{~g}$ [20]. Odds ratios were adjusted for age, education level, body mass index, waist-hip ratio, hypertension, diabetes, hypercholesterolemia, smoking, and family history of cardiovascular disease, when appropriate. Interaction between low birth weight and low education level was investigated by computing a dummy variable.

\section{Results}

The characteristics of 152 women with myocardial infarction and 568 control women at the index date are shown in Table 1. At the moment of completing the questionnaire, patients were aged 32-59 years (mean 50), and control women 25-60 years (mean 47 ). The mean body mass index was $25.1 \mathrm{~kg} / \mathrm{m}^{2}$ for the patients and $23.4 \mathrm{~kg} / \mathrm{m}^{2}$ for control women, mean difference $1.76 \mathrm{~kg} / \mathrm{m}^{2}$ (95\%CI $1.05-2.47), \mathrm{p}<0.001$. Ninety-seven patients (64\%) and 415 (73\%) controls could give their birth weight. Compared with control women, patients had a significantly lower mean birth weight (3214 vs. 3370 g, mean difference $-156.3 \mathrm{~g}(95 \% \mathrm{CI}-9.5$ to -303.1$)$. The odds ratio for myocardial infarction for children with a low birth weight ( $<2000 \mathrm{~g}$ ) compared to a birth weight $\geq 2000 \mathrm{~g}$ was 2.4 (95\%CI 1.0 to 5.8). After adjustment for putative confounders (age, education level, body mass index, waisthip ratio, hypertension, diabetes, hypercholesterolemia, smoking, and family history of cardiovascular disease) the odds ratio did not change. Odds ratios for myocardial infarction in different categories of birth weight as compared to the reference category (birth weight higher than 3884 g) were $1.3(95 \% \mathrm{CI} 0.5-3.3)$ for a birth weight 3500 to $3883 \mathrm{~g}, 1.4$ (95\%CI $0.6-3.4)$ for a birth weight 3200 to $3499 \mathrm{~g}, 1.7$ (95\%CI $0.6-5.1$ ) for a birth weight 3000 to $3199 \mathrm{~g}$, and 2.3 (95\%CI 1.0-5.4) for a birth weight lower than $3000 \mathrm{~g}$ (Table 2). The risk of myocardial infarction was 6.2 fold increased (95\%CI 2.7-13.9) among women with low birth weight and a low educational level compared to women with a high birth weight and a high educational level (reference category).

\section{Discussion}

In this case control study we have found that women with a low birth weight had a higher risk of myocardial infarction than women with a higher birth weight. The data confirm the association found in cohort studies [13-17] and as such support the 'fetal origins of adult disease' or 'Barker hypothesis'.

A limitation of the study is that we have no information on gestational age. However, recently it has been demonstrated that both children who had been born prematurely and children who are small for gestational age had a reduction in insulin resistance $[21,22]$. The self-report of birth weights as well as the rather high percentage of missing values for birth weight may also limit the study, but the random events among cases and controls cannot explain our results. Socio-economic factors associated with low birth weight are also associated to risk factors for arterial disease later in life. As pointed out by several others, it will be nearly impossible to disentangle these effects $[16,17]$. 
Table I: Characteristics of patients with a first myocardial infarction and control women

\begin{tabular}{lcc}
\hline Characteristic & Patients (N = I52) & Control women (N = 568) \\
\hline Age - yr (SD) & $42.1(0.5)$ & $38.6(0.3)$ \\
Caucasian ethnicity (\%) & $142(93)$ & $538(95)$ \\
Educational level & & $160(28)$ \\
- Primary school or less (\%) & $83(55)$ & $257(45)$ \\
- Secondary school (\%) & $52(34)$ & $149(26)$ \\
- Higher education or university (\%) & $17(11)$ & $218(39)$ \\
Current smokers (\%) & $128(84)$ & $35(6)$ \\
History of hypertension (\%) & $35(23)$ & $14(3)$ \\
History of hypercholesterolemia (\%) & $16(11)$ & $7(1)$ \\
History of diabetes (\%) & $8(5)$ & $194(36)$ \\
Family history of cardiovascular disease (\%) & $98(66)$ & $3370(659)$ \\
Birth weight-gram & & $3500(1500-5800)$ \\
- Mean (SD) & $3214(676)$ & $23.4(0.2)$ \\
- Median (range) & $3150(1500-5010)$ & $83.0(10.2)$ \\
Body Mass Index - kg/m ${ }^{2}-$ Mean (SD) & $25.1(0.4)$ & $0.81(0.008)$ \\
Waist circumference - cm (SD) & $89.5(13.1)$ & $480(85)$ \\
Waist/hip ratio (SD) & $0.85(0.006)$ &
\end{tabular}

Table 2: Odds ratios $(95 \% \mathrm{Cl})$ for myocardial infarction in quintiles of birth weight as compared to the reference category

\begin{tabular}{lc}
\hline Birth weight (g) & Odds Ratio (95\% Cl) \\
\hline$>3884$ & $I^{*}$ \\
$3500-3883$ & $1.3(0.5-3.3)$ \\
$3200-3499$ & $1.4(0.6-3.4)$ \\
$3000-3199$ & $1.7(0.6-3.4)$ \\
$<3000$ & $2.3(1.0-5.4)$ \\
\hline
\end{tabular}

* Reference category

In the present study we confirmed an interactive effect between low birth weight and a low educational level on the risk of myocardial infarction in women. However, when we adjusted for age, education level, body mass index, waist-hip ratio, hypertension, diabetes, hypercholesterolemia, smoking, and family history of cardiovascular disease, factors of which some may partly been seen as (the result of) socio-economic/environmental and genetic factors, we still observed an association between low birth weight and a higher risk of myocardial infarction. This is in agreement with others who also found that genetic and socio-economic circumstances at birth and in adult life can not completely explain the association between low birth weight and disease late in life $[10,16,17,23-25]$.

Among the proposed underlying biological mechanisms to explain the association is impaired endothelial development. Already at very young age, individuals with low birth weight exhibit endothelial dysfunction that persists into childhood and adult life, suggesting that endothelial dysfunction precedes the development of vascular related diseases later in life and represents the link between low birth weight and these diseases [26-32]. Furthermore, Smith et al. [33] found that mothers, who once gave birth to thin babies, have a higher risk of developing ischemic heart disease later in life. Therefore, these mothers seem to have, just as their children, an impaired endothelial function. If the impaired endothelial function is already manifest during the process of implantation, it might lead to inadequate development of the vasculature in the maternal part of the placenta, which enfeebles the function of the placenta resulting in low birth weight.

\section{Conclusions}

In conclusion, our study shows that a low birth weight $(<2000 \mathrm{~g})$ is associated with a 2.4 fold higher risk of myocardial infarction before the age of 50 as compared with a birth weight $\geq 2000 \mathrm{~g}$. Because the risk of cardiovascular disease is known to increase with an increasing number of risk factors, women with a low birth weight should try to avoid acquired risk factors, like smoking and obesity. In addition, extra attention should be given in detecting diabetes or hypertension at a later stage in life and in detecting exaggerated growth during childhood, as these individuals seem most prone to develop disease later on in life [[34-36]].

\section{Competing interests}

The author(s) declare that they have no competing interests. 


\section{Authors' contributions}

BT participated in the design, execution and analysis of the RATIO- study and drafted the manuscript.

KK analyzed the data and drafted the manuscript.

RH collected the data and performed statistical analyses.

FR initiated the study and helped to draft the manuscript.

FH participated in the design of the study and the writing of the paper.

\section{Acknowledgements}

This work was supported by the Netherlands Heart Foundation (97-063).

\section{References}

I. Barker DJ, Osmond C, Golding J, Kuh D, Wadsworth ME: Growth in utero, blood pressure in childhood and adult life, and mortality from cardiovascular disease. BMJ 1989, 298:564-567.

2. Barker DJ, Bull AR, Osmond C, Simmonds SJ: Fetal and placental size and risk of hypertension in adult life. BM] 1990, 30l:259-262.

3. Hales CN, Barker DJ, Clark PM, Cox LJ, Fall C, Osmond C, Winter PD: Fetal and infant growth and impaired glucose tolerance at age 64. BM] 1991, 303:1019-1022.

4. Barker DJ, Meade TW, Fall CH, Lee A, Osmond C, Phipps K, Stirling $Y$ : Relation of fetal and infant growth to plasma fibrinogen and factor VII concentrations in adult life. BMJ I992, 304: $148-152$.

5. Barker DJ, Hales CN, Fall CH, Osmond C, Phipps K, Clark PM: Type 2 (non-insulin-dependent) diabetes mellitus, hypertension and hyperlipidaemia (syndrome $X$ ): relation to reduced fetal growth. Diabetologia 1993, 36:62-67.

6. Valdez R, Athens MA, Thompson GH, Bradshaw BS, Stern MP: Birthweight and adult health outcomes in a biethnic population in the USA. Diabetologia 1994, 37:624-631.

7. McCance DR, Pettitt DJ, Hanson RL, Jacobsson LT, Knowler WC, Bennett PH: Birth weight and non-insulin dependent diabetes: thrifty genotype, thrifty phenotype, or surviving small baby genotype? BM] 1994, 308:942-945.

8. Whincup $P$, Cook D, Papacosta $O$, Walker $M$ : Birth weight and blood pressure: cross sectional and longitudinal relations in childhood. $B M$ I 1995, 3 I I:773-776.

9. Stein CE, Fall CH, Kumaran K, Osmond C, Cox V, Barker DJ: Fetal growth and coronary heart disease in south India. Lancet I996, 348: $1269-1273$

10. Frankel S, Elwood P, Sweetnam P, Yarnell J, Smith GD: Birthweight, body-mass index in middle age, and incident coronary heart disease. Lancet |996, 348:|478-|480.

II. Barker DJ: Fetal origins of coronary heart disease. BMJ 1995, 31 I: I71-174.

12. Paneth N, Susser M: Early origin of coronary heart disease (the "Barker hypothesis"). BMJ 1995, 3 I 0:4 I I-4 I2.

13. Barker DJ, Winter PD, Osmond C, Margetts B, Simmonds SJ: Weight in infancy and death from ischaemic heart disease. Lancet 1989, 2:577-580.

14. Osmond C, Barker DJ, Winter PD, Fall CH, Simmonds SJ: Early growth and death from cardiovascular disease in women. BM] 1993, 307:1519-1524.

I5. Eriksson JG, Forsen T, Tuomilehto J, Winter PD, Osmond C, Barker DJ: Catch-up growth in childhood and death from coronary heart disease: longitudinal study. $B M \mid$ | 999, 3 | 8:427-43|.

16. Rich-Edwards JW, Stampfer MJ, Manson JE, Rosner B, Hankinson SE, Colditz GA, Willett WC, Hennekens CN: Birth weight and risk of cardiovascular disease in a cohort of women followed up since 1976. BM] 1997, 3 1 5:396-400.

17. Leon DA, Lithell HO, Vagero D, Koupilova I, Mohsen R, Berglund L, Lithell UB, McKeigue PM: Reduced fetal growth rate and increased risk of death from ischaemic heart disease: cohort study of I5 000 Swedish men and women born I9 I5-29. BM] 1998, 3 | 7:24|-245.

18. Eriksson M, Tibblin G, Cnattingius S: Low birthweight and ischaemic heart disease. Lancet 1994, 343:73I.

19. Tanis BC, Van Den Bosch MA, Kemmeren JM, Cats VM, Helmerhorst FM, Algra A, Van Der Graaf Y, Rosendaal FR: Oral contraceptives and the risk of myocardial infarction. N Engl J Med 200I, 345: I787- 1793

20. World Health Organization: Low birth weight. A tabulation of available information. WHO Geneva 1992.

21. Bazaes RA, Alegria A, Pittaluga E, Avila A, Iniguez G, Mericq V: Determinants of insulin sensitivity and secretion in very-lowbirth-weight children. J Clin Endocrinol Metab 2004, 89:267-272.

22. Hofman PL, Regan F, Jackson WE, Jefferies C, Knight DB, Robinson EM, Cutfield WS: Premature birth and later insulin resistance. $N$ Engl J Med 2004, 35 I :2 I79-2 I86.

23. Frankel S, Elwood P, Sweetnam P, Yarnell J, Smith GD: Birthweight, adult risk factors and incident coronary heart disease: the Caerphilly Study. Public Health 1996, I I 0: I39- I 43.

24. Barker DJ, Gluckman PD, Godfrey KM, Harding JE, Owens JA, Robinson JS: Fetal nutrition and cardiovascular disease in adult life. Lancet 1993, 341:938-94I.

25. Poulter NR: Birthweights, maternal cardiovascular events, and Barker hypothesis. Lancet 200I, 357:1990-1991.

26. Martin H, Gazelius B, Norman M: Impaired acetylcholineinduced vascular relaxation in low birth weight infants: implications for adult hypertension? Pediatr Res 2000, 47:457-462.

27. Goh KL, Shore AC, Quinn M, Tooke JE: Impaired microvascular vasodilatory function in 3-month-old infants of low birth weight. Diabetes Care 200I, 24: I I02-I I07.

28. Leeson CP, Whincup PH, Cook DG, Donald AE, Papacosta O, Lucas $A$, Deanfield JE: Flow-mediated dilation in 9- to II-year-old children: the influence of intrauterine and childhood factors. Circulation 1997, 96:2233-2238.

29. Martin H, Hu J, Gennser G, Norman M: Impaired endothelial function and increased carotid stiffness in 9-year-old children with low birthweight. Circulation 2000, 102:2739-2744.

30. Leeson CP, Kattenhorn M, Morley R, Lucas A, Deanfield JE: Impact of low birth weight and cardiovascular risk factors on endothelial function in early adult life. Circulation 200I, I 03: 1 264-1268.

31. Goodfellow J, Bellamy MF, Gorman ST, Brownlee M, Ramsey MW Lewis MJ, Davies DP, Henderson $A H$ : Endothelial function is impaired in fit young adults of low birth weight. Cardiovasc Res 1998, 40:600-606.

32. McAllister AS, Atkinson AB, Johnston GD, McCance DR: Relationship of endothelial function to birth weight in humans. Diabetes Care 1999, 22:206 I-2066.

33. Smith GC, Pell JP, Walsh D: Pregnancy complications and maternal risk of ischaemic heart disease: a retrospective cohort study of I 29,290 births. Lancet 200I, 357:2002-2006.

34. Oren A, Vos LE, Uiterwaal CS, Gorissen WH, Grobbee DE, Bots ML: Birth weight and carotid intima-media thickness: new perspectives from the atherosclerosis risk in young adults (ARYA) study. Ann Epidemiol 2004, I4:8-16.

35. Forsen T, Eriksson J, Tuomilehto J, Reunanen A, Osmond C, Barker DJ: The fetal and childhood growth of persons who develop type 2 diabetes. Ann Intern Med 2000, I33:176-182.

36. Yajnik C: Interactions of perturbations in intrauterine growth and growth during childhood on the risk of adult-onset disease. Proc Nutr Soc 2000, 59:257-265. 